\title{
SEGURANÇA ALIMENTAR NO CAMPO E NA CIDADE EM NEPOMUCENO-MG
}

\section{Food Security in Countryside and in the City in Nepomuceno-MG}

\author{
Lucas Guedes Vilas Boas \\ Doutorando em Geografia na UFMG; Professor de Geografia do CEFET/MG \\ lucasguedes@nepomuceno.cefetmg.br
}

Artigo recebido em 10/08/2016 e aceito para publicação em 29/03/2017

DOI: $10.12957 /$ tamoios.2017.25062

\section{Resumo}

A alimentação é importante à saúde dos indivíduos, garantindo-lhes o suprimento de nutrientes indispensáveis ao funcionamento ideal de seus organismos. Destarte, este artigo analisa e compara a alimentação de um grupo populacional recém-migrado para a cidade com a de um conjunto de habitantes do campo, que não possua nenhum vínculo com procedimentos agroecológicos ou movimentos sociais. O local de estudo é o município de Nepomuceno, situado na mesorregião Campo das Vertentes, no estado de Minas Gerais. Para este objetivo, o trabalho utiliza a categoria de análise segurança alimentar, pois se julga que esta possui aspectos concernentes à relação entre agricultura e dieta alimentar e permite a averiguação de aspectos relacionados à alimentação e à saúde dos pesquisados. Para a averiguação da segurança alimentar dos grupos estudados, aplicou-se o questionário da Escala Brasileira de Insegurança Alimentar (EBIA) em quarenta imóveis camponeses e em quarenta domicílios citadinos de Nepomuceno. Ademais, outros aspectos que influenciam na segurança alimentar dos indivíduos, como o alcoolismo, a obesidade, o uso de agrotóxicos, os problemas psicológicos, entre outros, também foram avaliados.

Palavras-chave: Agricultura; Segurança Alimentar; Nepomuceno.

\begin{abstract}
Food is important to the health of individuals, guaranteeing their supply of nutrients essential for the optimal functioning of their bodies. Thus, this article analyzes and compares the food of a newly migrated population group to the city with a number of rural inhabitants who do not have any link with agroecological procedures or social movements. The study site is the municipality of Nepomuceno, located in the Campo das Vertentes middle region, in Minas Gerais. For this purpose, the study uses the analysis category of food security, because conceives it is thought that this has aspects concerning the relationship between agriculture and diet and allows the investigation of aspects related to food and health of responders. For the investigation of food security groups, applied the questionnaire of the Brazilian Food Insecurity Scale (EBIA) in forty farm properties and forty city homes of Nepomuceno. Furthermore, other aspects that influence food security of individuals, like alcoholism, obesity, use of pesticides, psychological problems, among others, were also evaluated.
\end{abstract}

Keywords: Agriculture; Food Security; Nepomuceno. 


\section{INTRODUÇÃO}

O presente artigo discute, com base na categoria segurança alimentar, as maneiras como as relações capitalistas de produção influenciam na alimentação dos seres humanos no campo e na cidade, reverberando em prejuízos nos regimes alimentares. Neste sentido, a pesquisa intentou compreender a influência da posse sobre a terra, importante meio de produção, na segurança alimentar dos sujeitos pesquisados neste estudo.

$\mathrm{Na}$ análise da situação de segurança alimentar foram estudados dois grupos populacionais distintos. O primeiro grupo é composto por uma população camponesa, sem liames com movimentos sociais e sem o uso das práticas agroecológicas, visando manter a fidedignidade da pesquisa, já que estudiosos como Ferrari (2010) e Costa Neto (2008), afirmam que a agroecologia é uma forma eficaz de se combater a insegurança alimentar. O segundo é constituído por um conjunto de pessoas migradas do campo para a urbe. Não se parte de um pressuposto já dado, como por exemplo, de que a alimentação no campo é mais saudável do que na cidade, visão vulgarmente popularizada e difundida.

A área de estudo é o município de Nepomuceno, localizado na mesorregião Campo das Vertentes (Figura 01), no estado de Minas Gerais, um dos maiores produtores de café do país. Nos últimos decênios, a região vem passando por um intenso processo de modernização e mecanização da agricultura e pela expansão da área ocupada pela lavoura cafeeira, o que vem aprofundando o êxodo rural e expulsando os pequenos proprietários rurais, vítimas da especulação fundiária.

Figura 01: Mapa de Localização do Município de Nepomuceno-MG
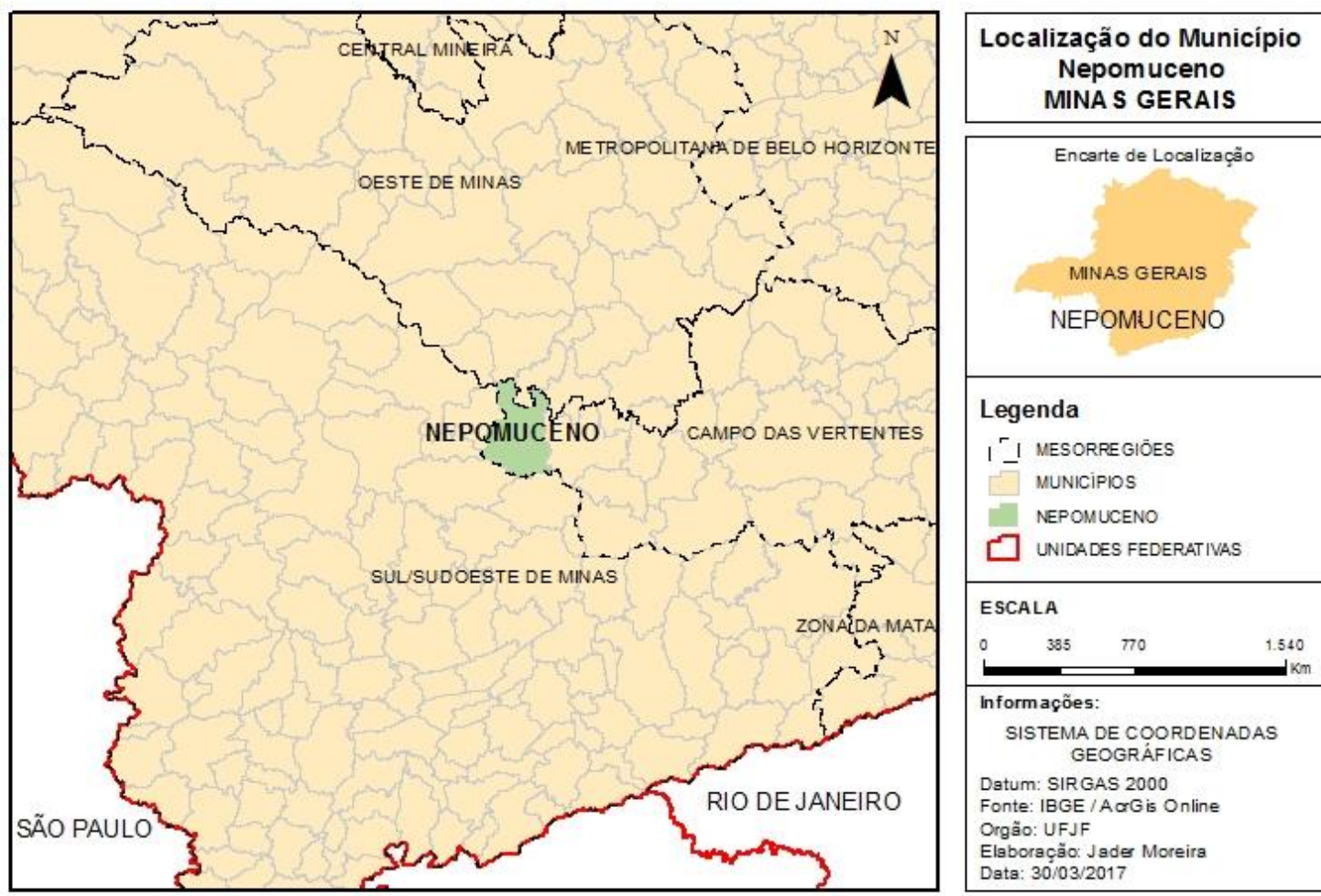

Fonte: IBGE/ArcGis Online

Autor: MOREIRA, Jader. 
Houve dificuldades na seleção das quarenta famílias residentes na cidade, visto que percentual representativo da população urbana de Nepomuceno possui propriedades rurais. Como um dos objetivos da pesquisa é comparar a situação alimentar entre famílias com posse sobre a terra enquanto meio produtivo e as que nada cultivam, tal fato tornou mais complexa a escolha dos grupos estudados.

Sublinha-se que o objetivo em estudar um grupo despossuído de meios produtivos é justamente averiguar como a falta de acesso à terra interfere na alimentação dos indivíduos, além de perceber qual o papel desempenhado pelas remunerações neste contexto. Conforme as idas aos imóveis rurais aconteciam, solicitava-se aos seus moradores que informassem sobre pessoas conhecidas que migraram recentemente para a cidade. Por conseguinte, o auxílio dos sujeitos envolvidos neste estudo foi fundamental na escolha dos domicílios urbanos investigados.

Pretendeu-se construir um comparativo entre a alimentação das duas populações estudadas, de modo a verificar se a migração para a cidade modificou substancialmente os modos alimentares dos migrantes, e se tal mudança foi positiva ou negativa. Tentou-se averiguar algumas de suas carências nutricionais, através de entrevistas e observações sobre seus modos alimentares e os nutrientes que compõem ou não sua base alimentar, procurando inquirir se há relações entre estas e a modernização da produção agrícola e/ou a migração campo-cidade.

\section{CAMINHO METODOLÓGICO}

Ao todo, quarenta famílias camponesas e quarenta famílias citadinas residentes no município foram analisadas quanto à situação de segurança alimentar, correlacionando-a com a questão agrícola local. A receptividade nas moradias estudadas foi boa, melhorando com o decorrer do tempo. No princípio, seus residentes respondiam às questões de forma sucinta, não se prolongando em suas falas. Com o desenrolar das visitas, a voz destes sujeitos foi tornandose ativa, com pronunciamentos longos, nos quais angústias e outros sentimentos eram revelados. Assim, a cada novo contato ampliava-se a percepção da realidade alimentar dos indivíduos pesquisados, bem como o envolvimento destes com o estudo. A participação dos sujeitos entrevistados na seleção das famílias investigadas foi de suma importância, pois ao término dos diálogos, indicavam outros imóveis com as características desejadas neste estudo.

Ademais, os quintais e lavouras das propriedades visitadas foram percorridos, no intuito de encontrar mais elementos e indícios que pudessem ampliar a compreensão acerca da agricultura e da alimentação dos sujeitos investigados. Os recipientes e embalagens dos insumos utilizados, tais como adubos químicos e pesticidas, também foram observados, com o intuito de verificar as empresas fabricantes. Nos dizeres de Chambers (1994), este procedimento integra a caminhada transversal ou participativa, na qual a área produtiva das propriedades é atravessada com os objetivos de investigar características ambientais e históricas e obter informações acerca dos processos e relações de trabalho e de produção, dos insumos utilizados na lavoura, entre outros.

Para averiguação dos quadros de insegurança alimentar nos sujeitos estudados, recorreuse também à Escala Brasileira de Insegurança Alimentar (EBIA), que mensura a situação de insegurança alimentar vivida pelas pessoas. A EBIA utiliza um questionário (Quadro 01) composto por quatorze perguntas. Para cada resposta afirmativa, soma-se um ponto. Caso a resposta seja negativa, nenhum ponto é acrescentado. Ao final do questionário, quanto mais pontos o indivíduo obteve, maior é o seu quadro de insegurança alimentar, havendo uma classificação do estado de insegurança alimentar, segundo a pontuação alcançada na escala. 


\section{Quadro 01: Questionário Aplicado - Escala Brasileira de Insegurança Alimentar}

\begin{tabular}{|c|c|c|}
\hline $\begin{array}{l}\text { As questões abaixo devem ser respondidas considerando-se os últimos noventa } \\
\text { dias antecedentes à entrevista: }\end{array}$ & Sim & Não \\
\hline $\begin{array}{l}\text { 1. Nos últimos três meses, os moradores deste domicílio tiveram preocupação } \\
\text { de que os alimentos acabassem antes de poderem comprar ou receber mais } \\
\text { comida? }\end{array}$ & & \\
\hline $\begin{array}{l}\text { 2. Nos últimos três meses, os alimentos acabaram antes que os moradores deste } \\
\text { domicílio tivessem dinheiro para comprar mais comida? }\end{array}$ & & \\
\hline $\begin{array}{l}\text { 3. Nos últimos três meses, os moradores deste domicílio ficaram sem dinheiro } \\
\text { para ter uma alimentação saudável e variada? }\end{array}$ & & \\
\hline $\begin{array}{l}\text { 4. Nos últimos três meses, os moradores deste domicílio comeram apenas } \\
\text { alguns alimentos que ainda tinham porque o dinheiro acabou? }\end{array}$ & & \\
\hline $\begin{array}{l}\text { 5. Nos últimos três meses, algum morador de } 18 \text { anos ou mais de idade deixou } \\
\text { de fazer uma refeição porque não havia dinheiro para comprar comida? }\end{array}$ & & \\
\hline $\begin{array}{l}\text { 6. Nos últimos três meses, algum morador de } 18 \text { anos ou mais de idade, alguma } \\
\text { vez comeu menos do que devia porque não havia dinheiro para comprar } \\
\text { comida? }\end{array}$ & & \\
\hline $\begin{array}{l}\text { 7. Nos últimos três meses, algum morador de } 18 \text { anos ou mais de idade, alguma } \\
\text { vez sentiu fome, mas não comeu, porque não havia dinheiro para comprar } \\
\text { comida? }\end{array}$ & & \\
\hline $\begin{array}{l}\text { 8. Nos últimos três meses, Algum morador de } 18 \text { anos ou mais de idade, alguma } \\
\text { vez, fez apenas uma refeição ao dia ou ficou um dia inteiro sem comer porque } \\
\text { não havia dinheiro para comprar comida? }\end{array}$ & & \\
\hline $\begin{array}{l}\text { 9. Nos últimos três meses, algum morador com menos de } 18 \text { anos de idade, } \\
\text { alguma vez, deixou de ter uma alimentação saudável e variada porque não } \\
\text { havia dinheiro para comprar comida? }\end{array}$ & & \\
\hline $\begin{array}{l}\text { 10. Nos últimos três meses, algum morador com menos de } 18 \text { anos de idade, } \\
\text { alguma vez, não comeu quantidade suficiente de comida porque não havia } \\
\text { dinheiro para comprar comida? }\end{array}$ & & \\
\hline $\begin{array}{l}\text { 11. Nos últimos três meses, alguma vez, foi diminuída a quantidade de } \\
\text { alimentos das refeições de algum morador com menos de } 18 \text { anos de idade, } \\
\text { porque não havia dinheiro para comprar comida? }\end{array}$ & & \\
\hline $\begin{array}{l}\text { 12. Nos últimos três meses, alguma vez, algum morador com menos de } 18 \text { anos } \\
\text { de idade deixou de fazer alguma refeição, porque não havia dinheiro para } \\
\text { comprar comida? }\end{array}$ & & \\
\hline $\begin{array}{l}\text { 13. Nos últimos três meses, alguma vez, algum morador com menos de } 18 \text { anos } \\
\text { de idade, sentiu fome, mas não comeu porque não havia dinheiro para comprar } \\
\text { comida? }\end{array}$ & & \\
\hline $\begin{array}{l}\text { 14. Nos últimos três meses, alguma vez, algum morador com menos de } 18 \text { anos } \\
\text { de idade, fez apenas uma refeição ao dia ou ficou sem comer por um dia inteiro } \\
\text { porque não havia dinheiro para comprar comida? }\end{array}$ & & \\
\hline
\end{tabular}

porque não havia dinheiro para comprar comida?

Fonte: Adaptado de: IBGE - INSTITUTO BRASILEIRO DE GEOGRAFIA E

ESTATÍSTICA. Pesquisa Nacional por Amostra de Domicílios (PNAD) de 2009. 2009.

Para além, outros elementos foram considerados na investigação sobre a insegurança alimentar, como a obesidade, o alcoolismo e o uso de agrotóxicos, pois estes repercutem imediatamente na qualidade dos regimes alimentares dos indivíduos, agravando as situações de insegurança alimentar. Ao passo que o tempo de contato com os grupos estudados se prolongava, mais informações sobre os assuntos supracitados eram obtidas, pois alguns destes temas envolvem elementos de ordem pessoal, podendo trazer algum constrangimento ao enunciador da fala. 
Foram realizadas entrevistas semiestruturadas e diálogos não estruturados com os sujeitos pesquisados, com o intuito de ampliar o conhecimento sobre suas dietas alimentares. Ambos os procedimentos não possuem uma estrutura inflexível, pois no âmbito da pesquisa qualitativa, buscam a adaptação ao contexto do diálogo. Acerca deste mote, Mann (1973) e Triviños (1995) enunciam que a entrevista semiestruturada, assim como o diálogo não estruturado, é composta por um grupo de elementos norteadores para as perguntas que serão efetuadas. Para além, os questionamentos não são predefinidos, tampouco precisam ser realizados rigorosamente na mesma sequência do planejamento. Por conseguinte, tais procedimentos ampliam a gama de assuntos tratados durante os relatos dos sujeitos entrevistados e favorecem a compreensão acerca de seu cotidiano. Neste sentido, o pesquisador, amparado pelo referencial teórico-metodológico, deve abordar os aspectos mais importantes ao seu estudo. Desta maneira, no estudo realizado, as entrevistas semiestruturadas e os diálogos não estruturados foram efetivados com o auxílio de um roteiro, o qual continha os principais elementos a serem avaliados nas propriedades.

No bojo da pesquisa qualitativa aqui realizada, a proposta de pesquisa e seus procedimentos foram transmitidos aos sujeitos investigados e definidos externamente a eles. Contudo, buscou-se manter o envolvimento e o compromisso com relação à população e à comunidade estudadas, que foram interrogadas e consultadas durante várias etapas do estudo. Ao final da investigação, uma cartilha com recomendações para a manutenção da segurança alimentar foi confeccionada e entregue aos sujeitos entrevistados durante a pesquisa.

Em consonância com Oliveira (2012), o estudo usou duas principais vertentes de fontes: a revisão literária, já explicada anteriormente; e a realidade empírica (em campo), por intermédio das idas aos locais estudados, da observação dos hábitos e das dietas alimentares dos homens e mulheres pesquisados, das entrevistas aplicadas e dos diálogos realizados, procurando-se assim, atar teoria à prática. $\mathrm{O}$ trabalho de campo e as visitas às propriedades agrícolas avaliadas foram realizados entre os meses de novembro de 2014 e julho de 2015.

Um tipo de pesquisa utilizado para a confecção destes escritos é a pesquisa bibliográfica (que se pauta na leitura, uso e análise de fontes científicas), a qual possui fontes secundárias a respeito do que é estudado. Oliveira (2012) também narra que a pesquisa qualitativa se aproxima de outros conhecimentos, além do científico, buscando um diálogo com os sujeitos envoltos na pesquisa.

Pessôa (2012) advoga que a pesquisa qualitativa é a mais apropriada para estudos complexos que não demandem quantificação. Para além, a escolha dos instrumentos metodológicos e de pesquisa deve ser adequada ao estudo, garantindo a confiabilidade das informações observadas em campo. Neste âmbito, a observação direta, as entrevistas semiestruturadas, os diálogos não estruturados e o trabalho de campo são procedimentos metodológicos característicos da pesquisa qualitativa empregados neste estudo, cujo intuito é realizar uma investigação qualitativa a partir dos conhecimentos da ciência geográfica.

Utilizou-se o estudo de caso múltiplo, que abarca mais de uma realidade para confrontar dados, algo valoroso à análise que se almeja realizar, pois a compreensão das diferenças existentes entre dessemelhantes realidades contribui para o avanço dos estudos pretendidos. Isto foi concretizado ao se confrontar as situações de segurança/insegurança alimentar do grupo camponês e do citadino envolvidos na pesquisa.

Embora o contato com os sujeitos da pesquisa tenha ocorrido meses atrás, preferiu-se realizar todas as entrevistas no mesmo mês, intentando trazer maior fidedignidade às informações obtidas. Assim sendo, após a averiguação do cotidiano de cada grupo familiar estudado, procedeu-se com a realização das entrevistas, cuja efetivação aconteceu no período de 02 a 29 de junho de 2015. Neste ponto, sublinha-se que todas as propriedades rurais dos sujeitos aqui estudados são minifúndios, pois são imóveis rurais com área inferior ou 
equivalente a um módulo fiscal, o qual, em Nepomuceno, corresponde a 26 hectares.

Temia-se que caso as entrevistas fossem realizadas em datas muito distantes, fatores de ordem climática (como estiagens duradouras ou precipitações intensas) ou macroeconômica (como um período de recessão econômica ou de elevada inflação), pudessem influenciar nos resultados encontrados, comprometendo a veracidade das informações adquiridas.

Desta maneira, optou-se por selecionar famílias de ganhos salariais mensais próximos, de modo a tentar minimizar possíveis falhas do trabalho, pois a discrepância nas remunerações reverbera diretamente no contexto alimentar de cada indivíduo. Assim sendo, o orçamento mensal per capita das famílias investigadas neste estudo está compreendido entre um e quatro salários mínimos, cujo valor total varia de 788,00 a 3152,00 reais.

Os questionários da EBIA foram aplicados com a presença de todos os familiares nos domicílios inquiridos, ressaltando-se que as respostas concerniriam aos noventa dias antecedentes à entrevista. Foram evitados comentários acerca das perguntas, almejando assim, não influenciar os interrogados em suas respostas. Somente foram tecidos alguns esclarecimentos quando os entrevistados apresentavam dúvidas quanto às perguntas lidas.

Por isso, o contato direto e mais prolongado com eles foi crucial à pesquisa, visto que possibilitou maior receptividade quanto aos objetivos deste estudo, além de propiciar maior detalhamento com relação às peculiaridades de cada indivíduo investigado. Como a pesquisa engloba temas embaraçosos, dentre os quais se realçam a dependência alcoólica e o excesso de peso, a confiança de seus integrantes do estudo foi imprescindível ao seu êxito.

\section{DESENVOLVIMENTO}

De antemão, é necessário salientar os empecilhos encontrados na procura por informações relativas às características alimentares e nutricionais dos grupos estudados. A escassez de dados atinentes às avitaminoses e às patologias por elas causadas, assim como a negligência de alguns órgãos e entidades, como a Secretaria Municipal de Saúde e a Secretaria Municipal de Assistência Social, na cessão dos mesmos, constituiu um obstáculo à realização desta pesquisa.

No Brasil, a disponibilidade de alimentos não deveria ser algo tão preocupante, devido à sua autossuficiência na produção de alguns gêneros, visto que o país é conhecido pela elevada fertilidade de seus solos e por ser um dos maiores exportadores de alimentos. Contudo, a problemática alimentícia ainda é preocupante, sobretudo quando se discute a questão do acesso aos alimentos.

Contribuindo majoritariamente para agravar as situações de insegurança alimentar está a carestia da alimentação, inclusive dos produtos básicos da dieta da população brasileira, cujos preços vêm apresentando constantes acréscimos. Destarte, há redução quantitativa e piora qualitativa na alimentação do povo tupiniquim, ampliando os casos de fome global e oculta.

Contudo, para Maluf e Speranza (2013), a crise alimentícia de proporções mundiais teve seus efeitos amenizados no território nacional, devido ao progressivo aumento do salário mínimo e aos programas de auxílio à alimentação, como o PNAE (Programa Nacional de Alimentação Escolar), o PAA (Programa de Aquisição de Alimentos) e o Programa Bolsa Família.

Sobre os dois primeiros projetos estatais mencionados, realça-se que muitos municípios brasileiros ainda não foram contemplados por seus benefícios. No tocante ao Programa Bolsa Família, devem ser destacados os vários casos de corrupção e fraudes envolvendo o repasse da verba, responsáveis por comprometer o acesso da população ao auxílio.

Já em Nepomuceno, o Programa Nacional de Alimentação Escolar (PNAE) e o Programa Bolsa Família já são uma realidade há alguns anos, englobando um percentual 
expressivo das instituições de ensino do município e da população carente ali residente. No município, a Secretaria Municipal de Desenvolvimento Social é incumbida da função de selecionar as famílias contempladas pelo Programa Bolsa Família e distribuir a quantia a elas destinada.

Alguns autores, como Maluf e Speranza (2013), apregoam que programas e auxílios governamentais colaboram na redução dos índices de insegurança alimentar. No entanto, nesta contextura, vários dos entrevistados descreveram a interrupção no recebimento da quantia custeada pelo famigerado programa Bolsa Família, repercutindo em prejuízos à situação alimentar das famílias, visto que a verba proveniente do governo federal auxiliava na ampliação da quantidade e da diversidade de alimentos consumidos.

Um dos indivíduos entrevistados narrou que embora o seu filho possua o cartão de beneficiário do projeto governamental Bolsa Escola, o valor financeiro correspondente ao auxílio nunca foi recebido, ratificando os inúmeros problemas existentes na distribuição da quantia destinada pelo Estado aos programas assistencialistas.

Quanto ao PNAE, a Secretaria Municipal de Agricultura e Meio Ambiente e a Empresa de Assistência Técnica e Extensão Rural do Estado de Minas Gerais (EMATER-MG), seguindo a tendência nacional do programa supracitado, firmaram uma parceria entre alguns agricultores familiares do município e as escolas da rede pública para o fornecimento de alimentos às crianças discentes, almejando a melhoria da alimentação dos infantes, com a intenção de ampliar a segurança alimentar no município.

Conforme afirmam Porto-Gonçalves e Alentejano (2009) e Maluf (1998), a agricultura familiar ainda é um dos pilares que sustentam a alimentação saudável, ampliando assim, a segurança alimentar das populações. Por conseguinte, as políticas públicas devem se destinar à melhoria das condições de vida e do orçamento dos pequenos produtores agrícolas, visto que são os gêneros oriundos de suas propriedades que abastecem a maioria das residências no Brasil. Para além, seus preços são expressivamente menores em comparação aos alimentos procedentes do exterior.

Outro ponto interessante versado pelos sujeitos investigados é a variação sazonal da qualidade da alimentação. De acordo com seus dizeres, como no verão não é época de colheita do café, principal gênero agrícola do município, a alimentação é empobrecida, pois se tornam escassos os recursos para aquisição de maior diversidade de gêneros. Tal fato ratifica a influência negativa da monocultura para a segurança alimentar, visto que uma produção policultora amplia as possibilidades de as safras ocorrerem em épocas diferentes do ano, asseverando alimentos e rendimentos de modo permanente aos agricultores.

Apesar da posse de um meio produtivo (a terra), no qual há a produção, a maioria dos pequenos produtores agrícolas inquiridos adquire a parcela majoritária dos alimentos consumidos pela família nos locais urbanos de venda, principalmente nos supermercados. Em imóveis agrícolas onde predominam as monoculturas, sobretudo as cafeeiras, não é incomum a compra de alimentos oriundos dos mercados da cidade, cujos índices de conservantes e outros elementos químicos, assim como o valor calórico e a taxa de gorduras, são deveras elevados. Além disto, as práticas monocultoras são nocivas à segurança alimentar da população, porque minoram a diversidade dos alimentos produzidos.

Para além, nas áreas agrícolas onde as monoculturas são hegemônicas, a renda salarial é crucial à garantia de uma boa alimentação, tanto no aspecto quantitativo, quanto no qualitativo. Notou-se na área rural do presente estudo, maior diversidade de gêneros ingeridos naqueles domicílios com maior rendimento médio mensal. Como uma quantidade representativa dos alimentos consumidos nas pequenas propriedades rurais é comprada na cidade, há a dependência do poder aquisitivo para assegurar uma alimentação saudável e variada. 
Portanto, as baixas remunerações mensais configuram-se como outro elemento danoso à qualidade da alimentação dos indivíduos pesquisados. Nesta esfera, alguns dos entrevistados contaram que se abstêm do consumo de alguns gêneros devido à ausência de dinheiro para adquiri-los. Destarte, tal fator acentua os estados de fome oculta no panorama local, porque minimiza a variedade de iguarias consumidas, decrescendo a diversidade de nutrientes ingeridos.

Esta circunstância foi comum principalmente nos imóveis onde não há criação de animais e naquelas cujas receitas mensais são inferiores à média dos demais. Deste modo, conforme pronuncia Hoffmann (1996), a pobreza é uma condicionante da insegurança alimentar, pois interfere diretamente na diversidade e na quantidade de alimentos componentes das dietas dos seres humanos.

O nível de escolaridade também influencia na problemática da segurança alimentar, pois os quadros mais agravados de insegurança alimentar preponderam nas famílias com menor grau de educação formal. De modo geral, este panorama é explicado pelo fato de, em escala mundial, os indivíduos com maior escolaridade receberem melhores remunerações, conforme advogam autores como Sorlie et. al (1995).

Para além, eles indicam que algumas enfermidades, sobretudo aquelas vinculadas a condições como a inexistência de saneamento básico e a subnutrição, prevalecem em pessoas com menos anos de instrução. Dentre as inúmeras patologias decorrentes dos problemas supracitados, Sorlie et. al (1995) destacam as parasitológicas, como a esquistossomose, a cólera, entre outras.

Além disto, a baixa escolaridade favorece a incompreensão dos valores nutricionais dos alimentos e da importância de uma dieta equilibrada. O limitado acesso às informações, aliado à falta de entendimento acerca destas, bem como a ausência de discernimento sobre os valores nutricionais dos alimentos, também coopera para a elevação da insegurança alimentar.

Assim sendo, em consonância com Sorlie et. al (1995) e Hoffmann (1996), observou-se entre as famílias inquiridas uma correlação entre os anos de estudo e o seu orçamento mensal, com as maiores remunerações sendo destinadas àqueles sujeitos com maior período de educação formal.

Por conseguinte, a escolaridade atua diretamente nas dietas dos grupos estudados, pois conforme já aventado, as receitas mensais são de grande valia para a segurança alimentar, ampliando a quantidade e a multiplicidade de alimentos consumidos. Por sua vez, entre as famílias visitadas, esta é maior naqueles domicílios com maiores faturamentos mensais e/ou anuais, se comparados aos demais.

Concordando com os dizeres de Josué de Castro (1957), em circunstâncias de alimentação deficitária, os seres humanos priorizam os gêneros mais calóricos, em detrimento dos demais, como maneira de assegurar a energia necessária para a execução dos afazeres diários. Dentre os produtos não consumidos pelas pessoas supramencionadas, destacam-se as carnes (sobretudo a bovina) e as frutas, cujo teor de nutrientes indispensáveis ao organismo humano é elevado, tais como diversas vitaminas e aminoácidos.

Assim como advoga Castro (1957), a exiguidade destes elementos no corpo humano pode incidir em diversas moléstias, como o beribéri, a pelagra, a anemia, o escorbuto, o raquitismo, entre outras enfermidades que avariam o pleno funcionamento do organismo. Para além, a carência proteica estorva o crescimento de ossos e músculos, interferindo em alguns casos, na estatura dos indivíduos, sobretudo nos infantes.

De modo consoante à discussão engendrada por autores como Harvey (2013), enunciase que a desregulamentação dos preços, típica da economia neoliberal e da acumulação flexível, prejudica tanto os consumidores dos alimentos, quanto os produtores familiares, elevando os índices de insegurança alimentar. Portanto, o Estado deveria agir na regulação dos preços 
alimentícios, de modo a evitar oscilações exorbitantes, as quais minimizam a qualidade dos regimes alimentares.

Ainda neste âmbito, a agricultura familiar municipal é muito subordinada ao setor urbano-industrial. Em virtude da compra de máquinas e insumos agrícolas, muitas famílias camponesas diminuíram a parcela do orçamento destinada à alimentação (COSTA NETO, 1998). Este panorama não difere do presenciado na realidade camponesa de Nepomuceno.

Alguns dos agricultores familiares pesquisados relataram o uso de parte do faturamento mensal ou anual para a compra de equipamentos e maquinários volvidos ao plantio e à colheita. Assim, ambicionam um retorno futuro, aguardando um acréscimo na produtividade e nos lucros decorrentes destes investimentos, mesmo que para isso tenham que reduzir temporariamente o percentual do orçamento destinado à compra de gêneros alimentícios. Em contrapartida, o dinheiro reservado à aquisição de alimentos é reduzido, bem como a variedade destes é escasseada, ampliando provavelmente os casos de fome oculta e de insegurança alimentar.

Os sujeitos estudados noticiaram que o processo de mecanização agrícola impulsionou o êxodo rural em Nepomuceno, pois diminuiu o número de postos de emprego no campo. Este estímulo à migração para a cidade se sucedeu em virtude da piora dos níveis de vida na área rural do município, decorrente da ampliação do desemprego no campo, resultando no agravamento da condição alimentícia da população e repercutindo em contração da segurança alimentar, pois minorou as receitas designadas à aquisição de alimentos.

Um percentual representativo dos indivíduos investigados neste estudo trabalha no Aviário Santo Antônio, sendo o emprego conseguido nesta empresa a motivação para o êxodo rural. O Aviário Santo Antônio é uma das maiores empresas brasileiras no setor granjeiro (OLIVEIRA, 2016), empregando aproximadamente novecentos trabalhadores apenas no município de Nepomuceno. É elevado o quantitativo de pessoas em Nepomuceno que migraram do campo para a cidade em busca de trabalho formal, principalmente para a empresa citada, a qual se configura como a maior indústria da cidade, além de ser a maior ofertadora de postos de emprego, contratando aproximadamente mil pessoas no município.

A ideia de que o agronegócio utiliza intensamente os insumos industriais, como os agrotóxicos e os transgênicos, é amplamente difundida e não está equivocada. Entretanto, o uso destes elementos oriundos da indústria não é restrito à agricultura de cunho empresarial, incidindo também sobre a pequena produção familiar (COSTA NETO, 1998). Intentando acréscimos na produtividade e, por conseguinte, no orçamento mensal, vários agricultores familiares aplicam os pesticidas em suas lavouras e adquirem as sementes transgênicas.

Desta maneira, em consonância com autores como Ferrari (2010) e Porto-Gonçalves (2006), apregoa-se que os agrotóxicos são danosos à segurança alimentar dos indivíduos, pois contaminam os animais, os vegetais cultivados, os recursos hídricos e edáficos, além de acrescerem a incidência de casos de neoplasias, falências renais, problemas cardiovasculares, entre outras enfermidades associadas ao uso contínuo destes praguicidas. Mesmo sabendo dos numerosos malefícios ocasionados pela sua utilização, a maioria dos agricultores familiares municipais prossegue com tal prática, no intuito de ampliarem a produtividade de suas lavouras, incrementando assim, os lucros logrados.

Neste âmbito, a agricultura familiar orgânica, vinculada a estratégias agroecológicas e voltada à conservação do meio ambiente, é praticada em algumas propriedades agrícolas do município. Há alguns incentivos da Prefeitura Municipal de Nepomuceno em prol da agroecologia, os quais ainda não conseguiram abranger parcela significativa dos agricultores municipais. Deste modo, a agricultura orgânica é pouco disseminada se comparada a outros métodos utilizados no cultivo, principalmente aqueles que utilizam diversos insumos urbanoindustriais e denigrem a natureza, assim como geram perdas qualitativas nos alimentos produzidos. 
Ademais, a imensa maioria dos pequenos produtores agrícolas inquiridos revelou a não utilização dos equipamentos de proteção individual (EPI's) no momento da aplicação dos agrotóxicos, aumentando assim, os perigos aos quais se expõem durante a jornada de trabalho e os riscos de contaminação no cultivo agrícola, tornando estas atividades bastante deletérias aos seus estados de saúde. Neste enredo, alguns trabalhadores expuseram situações nas quais se acidentaram, ao manusearem máquinas no labor empreendido nas lavouras.

Nesta área, ressalva-se o caso do agricultor internado às pressas no intervalo de execução desta pesquisa, em consequência do uso e da intoxicação por pesticidas. Na instituição de saúde, atribuíram a causa deste agravo à saúde do pequeno produtor aos praguicidas. Tal contaminação resultou em alergia e dores estomacais. Para além, vários pequenos produtores descreveram situações de mal-estar após o emprego de agrotóxicos nas lavouras.

Perante este quadro, um dos sujeitos da pesquisa afirmou que a justificativa de seu êxodo para a urbe foram os malefícios ocasionados pelo contato com os praguicidas, cujas avarias à sua saúde eram inúmeras, repercutindo em algumas internações hospitalares, sobretudo em virtude de intensas dores de cabeça e estomacais às quais era acometido.

O receio da contaminação de seus filhos, ainda crianças, pelos agrotóxicos, também contribuiu para sua mudança. Nos dias contemporâneos, um dos principais motivos para as migrações é a busca por melhorias na qualidade de vida, aspecto imperativo na averiguação da saúde humana, entendida neste estudo em seu conceito mais amplo.

No tocante ao assunto, Samsel e Seneff (2015) afirmam que o contato com o glifosato, princípio ativo da maioria dos herbicidas utilizados no município de Nepomuceno, reverbera em inúmeras enfermidades, como mal de Alzheimer, neoplasias, patologias cardiovasculares, disfunções respiratórias, má formação fetal e doença de Parkinson.

Nos últimos anos, houve grande crescimento do uso de agrotóxicos no Brasil, o qual se tornou o maior consumidor mundial de praguicidas. Inúmeros são os danos ambientais causados pela utilização dos pesticidas, como a contaminação dos solos, das águas superficiais e subterrâneas, a perda de biodiversidade, a redução de micronutrientes e a consequente esterilização dos solos, a mortandade da fauna e da flora aquática e terrestre, o surgimento de agentes patógenos resistentes aos agrotóxicos, entre outros. (ABRASCO, 2012a; 2012b; OLIVEIRA, 2016).

Pignati et. al (2007), Pessoa e Rigotto (2012) e Oliveira (2016) mostram que a utilização de agrotóxicos ocasiona danos irreparáveis à saúde humana e ao meio ambiente, constituindo a única atividade de contaminação proposital do ambiente de trabalho. Os autores ressaltam que os pesticidas não afetam apenas os trabalhadores que lidam diretamente com sua comercialização, transporte ou manipulação, mas também suas famílias, as quais residem em áreas próximas às lavouras onde o agrotóxico é pulverizado, armazenam estes insumos em suas residências e higienizam as vestimentas e os equipamentos de trabalho.

Neste cenário, a vulnerabilidade socioeconômica dos trabalhadores agrícolas contribui para a exposição e a contaminação em virtude do uso de agrotóxicos. Estudos efetuados pela Agência Nacional de Vigilância Sanitária (ANVISA) constataram inúmeros casos de contaminação por resíduos de agrotóxicos em diversos gêneros agrícolas e até mesmo no leite materno. Nos últimos anos, foram registradas diversas situações de intoxicação aguda e crônica em decorrência do contato com os pesticidas, algumas das quais culminaram no óbito do sujeito intoxicado (RIGOTTO, 2011; ABRASCO, 2012a). A permissão do uso em território brasileiro de agrotóxicos proibidos em diversos países agrava os riscos oferecidos ao meio ambiente e aos seres humanos (OLIVEIRA, 2016).

Através da observação concretizada durante o percurso realizado pelas lavouras e quintais, observou-se que os praguicidas e os fertilizantes químicos utilizados são oriundos de um restrito grupo de multinacionais, como a Bayer, a Basf, a Monsanto, a Syngenta, a Dow 
Chemical e a Cargill, as quais compõem o oligopólio do setor no Brasil e no mundo, em virtude de processos como a fusão e a aquisição de empresas menores (BOMBARDI, 2011; ABRASCO, 2012a; OLIVEIRA, 2016).

No entanto, em diálogos com os produtores agrícolas locais, a maioria deles manifestou desconhecimento com relação aos malefícios ambientais acarretados pelo uso destes venenos. A título de exemplo, praticamente todos não sabiam que os resíduos dos agrotóxicos permanecem por muitos anos na terra, nem que contaminam os lençóis freáticos e, portanto, os recursos hídricos adjacentes ao imóvel agrícola, degradando o meio ambiente como um todo. Estas agressões ambientais, favorecedoras de processos como a desertificação, a erosão, a chuva ácida e a lixiviação, rebaixam os índices de segurança alimentar, já que as águas e os solos são de extrema relevância nos regimes alimentares humanos, interferindo diretamente na produtividade agrícola, bem como na qualidade dos víveres consumidos.

Não obstante, há um cenário paradoxal no campo nepomucenense. Embora tenham o conhecimento dos males ocasionados pelo uso reiterado de praguicidas à saúde humana, alguns agricultores familiares defenderam veementemente sua utilização, argumentando que foram eles os responsáveis pela melhoria do nível de vida entre os pequenos produtores municipais, os quais possuíam uma qualidade de vida inferior em tempos pretéritos.

De acordo com suas palavras, foram os avanços produtivos derivados da inserção destes insumos industriais na lavoura municipal que provocaram a atenuação do êxodo rural, visto que elevaram os orçamentos no campo em Nepomuceno, colaborando para a melhoria das condições de vida, inclusive da alimentação, nas moradias rurais do município.

As moléstias de cunho psicológico também se entrelaçam com a problemática da insegurança alimentar. Neste sentido, conforme advogam escritores como Segall-Corrêa (2007) e Mundo-Rosas et.al (2013), pode-se afirmar que os aspectos psicológicos dos indivíduos afetados pelo estado de insegurança alimentar constituem-se num ponto interessante para ser analisado no trabalho de campo. Neste domínio, os receios referentes à questão alimentícia podem gerar enfermidades de cunho ansiolítico, depressões, entre outras.

Em vista disso, buscou-se avaliar o aspecto psicológico dos indivíduos da pesquisa, sobretudo relacionando-o à alimentação, por meio de seus relatos nas entrevistas semiestruturadas e nos diálogos não estruturados. Dentre as quarenta famílias analisadas na área rural do município, em dez ( $25 \%$ do total) delas foram descritos casos de depressão, a maioria em homens na faixa etária entre 40 e 60 anos, cujo período de trabalho no campo é prolongado, de décadas. Para além, em uma residência, de acordo com seus moradores, uma mulher está impedida de trabalhar faz anos, pois sofre de estados depressivos agudos.

No tocante aos quarenta imóveis urbanos averiguados neste estudo, em oito (20\%) deles há algum indivíduo com alguma enfermidade de cunho psicológico. Em seis deles, as pessoas com patologias psicológicas são mulheres acometidas por depressão. Neste quesito, há uma diferença entre o campo e a cidade em Nepomuceno, pois enquanto na área rural do município os quadros depressivos prevalecem em homens, na cidade, predominam em indivíduos do sexo feminino. Ressalva-se, em consonância com os depoimentos dos entrevistados e por intermédio da análise dos dados acima elencados, que o percentual de pessoas acometidas por estas moléstias é bastante expressivo na conjuntura local, ampliando-se nos últimos anos.

A tabela abaixo condensa os resultados obtidos para as residências estudadas, tanto para os casos de alcoolismo, quanto para as situações de obesidade. Ela apresenta o quantitativo total e percentual das moradias com habitantes alcoólatras e obesos, no campo e na cidade, aspirando facilitar a análise destes fenômenos na conjuntura municipal. 
Tabela 01: Quantitativo Absoluto e Relativo dos Domicílios Pesquisados com Casos de Alcoolismo e Obesidade em Nepomuceno - MG

\begin{tabular}{|c|c|c|}
\hline & Campo & Cidade \\
\hline Obesidade & $10(25 \%)$ & $10(25 \%)$ \\
\hline Alcoolismo & $7(17,5 \%)$ & $4(10 \%)$ \\
\hline
\end{tabular}

Fonte: Pesquisa de Campo Realizada entre novembro de 2014 e julho de 2015 Organização: Do Autor

Com relação aos dados acima expostos, algumas das pessoas entrevistadas no campo nepomucenense relataram que há tempos o alcoolismo atingia parcela expressiva dos moradores da área rural do município, desestruturando as relações familiares camponesas e influenciando no trabalho e no rendimento financeiro de vários agricultores locais.

Neste ponto, muitos disseram que em suas próprias residências existem ex-alcoólatras. No entanto, afirmaram que contemporaneamente houve significativa redução dos casos de dependência alcoólica no campo municipal, indicando aumento da qualidade de vida da população, bem como melhorias nos quadros de segurança alimentar.

Nesta esfera, das quarenta famílias camponesas estudadas, sete $(17,5 \%)$ possuem casos de alcoolismo entre seus habitantes. Deste total, em seis residências os moradores alcoólatras são adultos jovens, com faixa etária entre 18 e 25 anos. Tal fato é alarmante, visto que como muitos camponeses pormenorizaram a vasta incidência desta moléstia na área rural de Nepomuceno décadas atrás, com expressivo decréscimo nos anos recentes, isto pode assinalar uma nova explosão na quantidade de alcoólatras nas áreas rurais do município.

Já na cidade, observaram-se quatro (10\%) domicílios com presença de pessoas alcoólatras. Em todos eles, os indivíduos acometidos pela dependência alcoólica são homens. Assim como no campo, os moradores urbanos arrolaram inúmeros exemplos de ex-alcoólatras em seus imóveis. Além disto, também narraram que a presença de um alcoólatra na residência deteriora consideravelmente as condições de vida e de alimentação de seus habitantes, sobretudo em virtude das perdas financeiras. Assim sendo, pode-se enunciar que, entre as famílias estudadas em Nepomuceno, o alcoolismo é maior no campo em comparação à cidade, impactando majoritariamente representantes do sexo masculino.

Destarte, sublinha-se que o alcoolismo é um problema à segurança alimentar, porque compromete uma parcela do orçamento familiar com a aquisição de bebidas alcoólicas. Tal fato foi confirmado por alguns depoimentos concedidos nos diálogos efetuados com os sujeitos da pesquisa. Ademais, além dos malefícios e das enfermidades decorrentes da ingestão excessiva de álcool, alguns destes drinques possuem alto valor calórico, prejudicando a saúde dos indivíduos e contribuindo para o acréscimo nas taxas de obesidade.

Em algumas das propriedades examinadas, seus moradores avisaram que os indivíduos alcoólatras residentes no domicílio designavam quantidade significativa do ordenado mensal para a compra de bebidas alcoólicas, comprometendo o total despendido para a aquisição de alimentos. Este fato deteriora a situação alimentar nestes imóveis, visto que os mais afetados pela dependência do álcool são os homens adultos, cujas remunerações são, em geral, a base do sustento familiar, sobretudo nas áreas rurais.

Segundo indicam Fonseca et. al (2013) e Mundo-Rosas et. al (2013), a obesidade é um indicativo do estado de insegurança alimentar, pois aponta, em geral, falhas nas dietas alimentares dos indivíduos acometidos pelo excesso de peso, além de ampliar a probabilidade de contrair diversas enfermidades. Em conformidade com a OMS (Organização Mundial da Saúde), pode-se dizer que a pessoa obesa é aquela com IMC (Índice de Massa Corporal) superior a 30. Tal indicador é obtido através da divisão do peso em quilogramas pelo quadrado 
da altura do indivíduo averiguado (OMS, 2015).

Os dados da própria OMS (2015) indicam a existência de mais de 600 milhões de obesos mundo afora, sendo que de 1980 até 2014, este quantitativo duplicou. Para além, a entidade demonstra uma tendência à elevação do número de obesos em escala global, principalmente devido a fatores, como a paulatina sedentarização do ser humano, a ingestão excessiva de açucares, gorduras e alimentos hipercalóricos, entre outros.

A própria entidade corrobora que a obesidade acentua as chances de óbito prematuro, bem como alarga a possibilidade de ocorrência de patologias cardiovasculares, psicológicas, respiratórias, entre outras. Portanto, este quadro clínico é um grave fator de risco à saúde humana. Ademais, inúmeros países subdesenvolvidos, famosos pelo pauperismo extremo, convivem com um panorama paradoxal. Concomitantemente a taxas alarmantes de subnutrição, desnutrição e doenças infecciosas, se expandiram os casos de obesidade, ampliando a probabilidade de moléstias crônicas.

Obviamente, o IMC não é um indicador perfeito para a análise do excesso de peso ou do teor de gorduras no organismo humano. Todavia, devido à dificuldade no uso de outros métodos, assim como seu alto custo, o Índice de Massa Corporal ainda é o principal instrumento para a avaliação da obesidade em âmbito mundial e nacional, sendo utilizado por diversos órgãos e entidades de renome, como a Organização Mundial da Saúde (OMS), o Instituto Brasileiro de Geografia e Estatística (IBGE), entre outros.

Por conseguinte, nos domicílios examinados, a obesidade foi aferida através do cálculo do IMC dos sujeitos nela residentes. Associados às falas dos entrevistados, uma balança digital portátil e uma fita métrica foram utilizadas, respectivamente, para mensurar o peso e a altura deles. Das famílias entrevistadas no campo, dez (25\% do total) apresentam quadros de obesidade entre seus integrantes. Tais casos predominam entre as mulheres das moradias em questão, visto que em nove dos dez imóveis, os indivíduos obesos são as mulheres.

Em diálogos com os moradores destes imóveis, constatou-se maior realização de atividades físicas nos homens. Para além, há uma nítida divisão de gênero no tipo de trabalho realizado. Na maioria das vezes, aos homens das residências são incumbidas as atividades com maior exigência de força braçal. Já às mulheres, são delegadas funções vinculadas principalmente ao ambiente doméstico.

Enquanto isto, entre as quarenta famílias urbanas analisadas nesta pesquisa, dez (25\%) possuem membros obesos, mesma quantidade identificada nos imóveis rurais investigados. Tanto na cidade, quanto no campo, a maioria dos indivíduos com excesso de peso revelou consumo exacerbado de alimentos ricos em açucares e gorduras, cujas consequências negativas ao organismo humano são inúmeras, como por exemplo, aumento da possibilidade de ocorrência de enfermidades cardiovasculares, diabetes e obesidade, a qual pode provocar diversas outras patologias, maximizando os riscos de óbito, conforme já aludido anteriormente.

$\mathrm{Na}$ maioria dos imóveis camponeses visitados, há cultivo de frutas com alto teor de vitamina $\mathrm{C}$, como a laranja e a tangerina, acarretando, conforme afirmaram os próprios residentes do campo, no alto consumo destas. Além disto, é corriqueira a existência de culturas de hortaliças, como alface, couve, salsa, entre outras, cujo índice de vitaminas é elevado.

Nas propriedades rurais onde há criação de animais, observou-se consumo satisfatório de carne e outros elementos de origem animal, tanto diariamente, quanto semanalmente. Dentre os animais criados, destacam-se os rebanhos aviário, suíno e bovino, com predominância dos galináceos, os quais são a principal fonte animal presente nas dietas dos camponeses em Nepomuceno.

No entanto, em algumas propriedades visitadas, apesar da posse sobre a terra enquanto meio produtivo, não havia o cultivo, tampouco o consumo de gêneros como frutas, verduras ou legumes. Tal situação indica que nem sempre a propriedade da terra é garantia de uma 
alimentação saudável e variada.

Já na área urbana de Nepomuceno, o contexto não é distinto do visualizado em algumas moradias camponesas vistoriadas. Prevalece entre as famílias citadinas do município o ínfimo consumo de alimentos de origem vegetal, principalmente de frutas. Como o orçamento é insuficiente para assegurar um regime alimentar bastante diverso, os habitantes da cidade preferem a compra de uma variedade limitada de gêneros, cujos índices calóricos são elevados, em detrimento de produtos mais saudáveis, como frutas e legumes.

Desta maneira, pode-se articular que de modo geral, a alimentação da parcela da população nepomucenense estudada é carente principalmente em gêneros de origem animal, ricos em proteínas, e frutas, cuja ingestão se mostrou mínima em muitos imóveis visitados. Cabe frisar que a situação mencionada é mais grave na cidade, onde a desposse dos meios produtivos (solo agricultável) torna seus habitantes dependentes dos ordenados mensais para aquisição dos alimentos. Neste enredo, a compra de frutas e carnes, cujos preços são onerosos, é rara no decurso do mês.

A ingestão excessiva de açucares, de gorduras e de frituras é prejudicial à saúde dos seres humanos, deteriorando os quadros de insegurança alimentar e de fome oculta, pois ampliam a probabilidade do indivíduo adquirir diversas doenças, além de acentuar os estados de obesidade (SORLIE ET. AL, 1995).

Assim sendo, tais consumos foram inquiridos no estudo realizado, através da análise do cotidiano alimentar dos grupos pesquisados, cuja verificação ocorreu através das descrições fornecidas e da observação dos alimentos consumidos por eles. Deste modo, a ingestão destes elementos no campo, assim como na cidade, em Nepomuceno se mostrou, em alguns casos, excessiva.

Na maioria dos domicílios onde se constatou quadros de obesidade, também se verificou consumo abundante de açucares e gorduras nos regimes alimentares, podendo ser esta a causa para algumas patologias existentes em seus moradores. Para além, no tocante à ingestão de açucares, notou-se maior abundância nos imóveis citadinos, quando confrontados com os rurais. Este evento ocorre principalmente em virtude da frequente presença de alimentos industrializados em suas mesas, como refrigerantes, sorvetes, entre outros, cujo teor de açucares é elevado.

Presenciou-se no campo maior preocupação com o teor de gorduras e açucares dos gêneros consumidos, em detrimento da cidade. De modo geral, os indivíduos camponeses pesquisados demonstraram maior interesse e conhecimento em relação aos nutrientes contidos nos alimentos. Em alguns casos, os entrevistados mencionaram que se abstêm ou evitam determinadas iguarias, devido às substâncias nelas inclusas. Talvez possa ser esta a explicação para o fato supramencionado.

A respeito da alimentação, em consonância com Freitas (2003), enfatiza-se seu estreito vínculo com a questão palatina, pois o sabor dos gêneros consumidos é componente importante dos regimes alimentares. Desta maneira, esta situação foi avaliada nas residências pesquisadas, notando-se que na maioria delas, alguns alimentos, principalmente verduras e legumes, cujo teor de nutrientes é elevado, não são ingeridos pelos seus habitantes porque não agradam ao paladar. Em vista disso, pode-se afirmar que os temperos e sabores possuem relevância na culinária e na dieta do município analisado.

Ademais, assim como propagam Vervoort et. al (2014), elementos vinculados ao clima, como as recentes mudanças climáticas globais, podem inflacionar as taxas de insegurança alimentar, degenerando os regimes alimentares em escala mundial. Assim sendo, vários pequenos agricultores narraram prejuízos às safras decorrentes das alterações temporais, principalmente em virtude da irregularidade das chuvas. Houve ampliação da duração dos períodos de estiagem, reverberando em atrasos e perdas nas colheitas. 
Para além, muitos relatos confirmaram expressivos decréscimos nos orçamentos, derivados da inconstância pluviométrica, cujos danos superam a simples redução das receitas. Por si só, este fato já compromete a dieta alimentar dos indivíduos pesquisados, pois percentual relevante dos víveres por eles consumidos é procedente dos mercados urbanos e adquirido através da compra.

Da mesma maneira, como a parcela majoritária dos camponeses em Nepomuceno retira porcentagem significativa dos gêneros contidos em seus regimes alimentares da produção familiar, tal conjuntura é ainda mais danosa à sua alimentação, sobretudo quanto à diversidade, podendo repercutir na ampliação dos estados de fome oculta.

Por conseguinte, os sujeitos desta pesquisa noticiaram que a volatilidade dos eventos climáticos repercutiu em notáveis prejuízos às suas dietas alimentares, pois ao diminuírem a produção total das propriedades, tais oscilações minoraram a multiplicidade de gêneros consumidos e incidiram na contração da verba destinada à aquisição de alimentos.

Conforme afirmam Hoffmann (1996) e Maluf (1998), diversos fatores influenciam na situação de segurança alimentar das populações. Nesta perspectiva, a Escala Brasileira de Insegurança Alimentar, formulada por um conjunto de pesquisadores de instituições de pesquisa nacionais, é um instrumento criado com o intuito de avaliar a segurança alimentar nos domicílios brasileiros, agrupando em seu questionário alguns elementos associados à (in) segurança alimentar (SEGALL-CORRÊA, 2007).

\section{EBIA E A SEGURANÇA ALIMENTAR EM NEPOMUCENO}

Em face dos tópicos supramencionados e discutidos, o desenlace desta pesquisa advém com a apresentação e a análise das informações referentes à aplicação do questionário da Escala Brasileira de Insegurança Alimentar. Em relação à EBIA, Segall-Corrêa e Marin-Leon (2009) dissertam que o indicador é auxilia os estudos sobre insegurança alimentar no país, possibilitando avaliar se as políticas estatais destinadas à questão alimentar resultaram em melhorias na alimentação da população brasileira.

No questionário da EBIA, o indivíduo e/ou o domicílio podem apresentar quatro níveis de segurança alimentar, descritos a seguir. $\mathrm{O}$ valor total da pontuação da escala corresponde à soma dos pontos obtidos, oscilando entre zero (0) e quatorze (14). Destarte, estas são as quatro categorias de classificação da EBIA:

Segurança alimentar (SA) - Ocorre quando todas as respostas aos itens presentes no questionário da EBIA são negativas, isto é, quando a pontuação na escala é de zero. Assim, o domicílio ou o indivíduo que se encontre em segurança alimentar, não sofre com problemas no acesso aos alimentos, seja em qualidade ou em quantidade. Além disto, no que tange à questão psicológica, não há o temor de que possam faltar alimentos futuramente.

Insegurança alimentar leve (IL) - Acontece quando uns quantitativos de uma a cinco questões foram respondidas de maneira positiva. Neste quadro, já há o receio dos indivíduos de uma possível ausência de alimentos num futuro breve, e eles planejam o orçamento e o cotidiano domésticos para elevarem a duração dos alimentos.

Insegurança alimentar moderada (IM) - Advém quando de seis a nove interrogações da EBIA foram respondidas positivamente. Nestes casos, a qualidade da alimentação já é bastante comprometida, pois o objetivo primordial é sanar a necessidade quantitativa de alimentos. Neste estágio, já existe uma diminuição na quantidade e na variedade de alimentos consumidos entre os adultos da residência, que privilegiam a alimentação das crianças, por estas apresentarem 
uma saúde mais frágil.

Insegurança alimentar grave (IG) - Paira nas residências e nos indivíduos que responderam positivamente de dez a quatorze perguntas. Nesta condição, há restrição quantitativa de alimentos, acarretando em situação de fome, tanto entre adultos, quanto em crianças da família. É, indubitavelmente, o foco de maior atenção governamental nas políticas públicas elaboradas neste setor.

Deste modo, utilizaram-se os parâmetros fornecidos pela EBIA, abaixo representados no quadro 02, para mensurar a situação de segurança alimentar dos grupos estudados.

Quadro 02: Valores para a Classificação do Estágio de Segurança Alimentar segundo as Categorias Estabelecidas pela EBIA

\begin{tabular}{|c|c|c|}
\hline $\begin{array}{c}\text { Classificação do estágio } \\
\text { de segurança alimentar }\end{array}$ & $\begin{array}{c}\text { Domicílios com pelo } \\
\text { menos um morador com } \\
\text { idade inferior a } \mathbf{1 8} \text { anos }\end{array}$ & $\begin{array}{c}\text { Domicílios com todos os } \\
\text { moradores de 18 anos de } \\
\text { idade ou mais }\end{array}$ \\
\hline Segurança Alimentar & 0 pontos & 0 pontos \\
\hline $\begin{array}{c}\text { Insegurança Alimentar } \\
\text { Leve }\end{array}$ & 1 a 5 pontos & 1 a 3 pontos \\
\hline $\begin{array}{c}\text { Insegurança Alimentar } \\
\text { Moderada }\end{array}$ & 6 a 9 pontos & 4 a 5 pontos \\
\hline $\begin{array}{c}\text { Insegurança Alimentar } \\
\text { Grave }\end{array}$ & 10 a 14 pontos & 6 a 8 pontos \\
\hline
\end{tabular}

Fonte: Adaptado de: IBGE - INSTITUTO BRASILEIRO DE GEOGRAFIA E ESTATÍSTICA. Pesquisa Nacional por Amostra de Domicílios (PNAD) de 2009. 2009.

Concernindo às quarenta famílias camponesas pesquisadas quanto ao estado de segurança alimentar, em consonância aos critérios da EBIA, foram encontrados os seguintes resultados, ilustrados na tabela 02 :

Tabela 02: Total Absoluto e Percentual dos Estados de Segurança Alimentar das Quarenta Famílias Camponesas Investigadas em Nepomuceno - MG

\begin{tabular}{|c|c|}
\hline Situação de Segurança Alimentar & Total (Absoluto e Relativo) \\
\hline Segurança Alimentar & $23(57,5 \%)$ \\
\hline Insegurança Alimentar Leve & $17(42,5 \%)$ \\
\hline Insegurança Alimentar Moderada & $0(0 \%)$ \\
\hline Insegurança Alimentar Grave & $0(0 \%)$ \\
\hline \multicolumn{2}{|c|}{ Fonte: Pesquisa de Campo Realizada entre novembro de 2014 e julho de 2015} \\
Organização: Do Autor
\end{tabular}

Portanto, através da análise da tabela acima, percebe-se a inexistência de casos de insegurança alimentar moderada ou grave nas residências camponesas pesquisadas no município de Nepomuceno. No tocante à insegurança alimentar leve, dezessete $(42,5 \%)$ das quarenta famílias estudadas estão nesta situação, denotando problemas de ordem qualitativa em seus regimes alimentares. Já na maioria das moradias, totalizando vinte e três $(57,5 \%)$, seus habitantes se encontram em estado de segurança alimentar, sem quaisquer problemas em seus regimes alimentares. 
Assim, com relação ao tema discutido, o campo nepomucenense ainda está distante do cenário ideal (no qual todas as famílias estariam em segurança alimentar), e abaixo do percentual de segurança alimentar encontrado no país, segundo os dados divulgados pelo IBGE (2014). Além disto, também está aquém dos números referentes à população rural brasileira, a qual possui maiores taxas de insegurança alimentar que a urbana.

Neste âmbito, alguns elementos atuantes no acréscimo da insegurança alimentar no campo em Nepomuceno são o diminuto rendimento mensal da maioria dos pequenos produtores agrícolas municipais, a permanência de práticas monocultoras, a ínfima pluralidade de gêneros alimentícios lavrados e consumidos, a recente irregularidade nas condições térmicas e pluviométricas, entre outros.

Não obstante, os fatores acima elencados coadunam-se no agravamento do estado alimentar dos cidadãos nepomucenenses. A título de exemplo, a instabilidade climática origina prejuízos financeiros aos agricultores, culminando na redução da quantidade de víveres produzidos, bem como na minoração do sortimento de gêneros ingeridos, o qual também é reduzido pela propagação das atividades monocultoras.

Os itens 01 e 03 do questionário da EBIA foram os que apresentaram maior quantidade de respostas positivas entre os habitantes rurais de Nepomuceno. Referem-se, respectivamente, ao receio de que os alimentos acabem antes de providenciarem mais comida e à ausência de recursos financeiros para garantia de uma alimentação saudável e variada.

Este fato assinala que na área rural de Nepomuceno, os principais problemas relacionados ao contexto alimentar estão atrelados à questão da renda salarial e da diversidade de gêneros consumidos. Percebe-se piora gradativa na qualidade e na multiplicidade de alimentos constituintes das dietas à proporção que as receitas mensais vão diminuindo. Portanto, mesmo nos imóveis camponeses onde existem lavouras cultivadas, a questão financeira é relevante para a variedade da alimentação e, por conseguinte, para a segurança alimentar.

Já com relação aos domicílios citadinos analisados no município de Nepomuceno, a tabela 03 aclara e sumariza os quadros de segurança alimentar encontrados:

Tabela 03: Total Absoluto e Percentual dos Estados de Segurança Alimentar das Quarenta Famílias Citadinas Investigadas em Nepomuceno - MG

\begin{tabular}{|c|c|}
\hline Situação de Segurança Alimentar & Total (Absoluto e Relativo) \\
\hline Segurança Alimentar & $16(40 \%)$ \\
\hline Insegurança Alimentar Leve & $19(47,5 \%)$ \\
\hline Insegurança Alimentar Moderada & $5(12,5 \%)$ \\
\hline Insegurança Alimentar Grave & $0(0 \%)$ \\
\hline
\end{tabular}

Fonte: Pesquisa de Campo Realizada entre Novembro de 2014 e Julho de 2015

Organização: Do Autor

Portanto, na urbe nepomucenense, mais da metade das habitações investigadas apresenta insegurança alimentar, totalizando vinte e quatro $(60 \%)$ das quarenta moradias inquiridas. Destas, em dezenove (47,5\%) pairam situações de insegurança alimentar leve, enquanto em cinco $(12,5 \%)$ há estados de insegurança alimentar moderada. Somente dezesseis (40\%) dos quarenta domicílios examinados exibiram quadros de segurança alimentar entre seus residentes.

Detalhando as informações conseguidas, percebe-se que os índices de insegurança alimentar entre os moradores urbanos de Nepomuceno estão acima das cifras diagnosticadas para a realidade nacional, segundo os valores divulgados pelo IBGE (2014). As baixas 
remunerações recebidas, as quais interferem diretamente na parca variedade de alimentos consumidos, assim como a dependência do poder aquisitivo para a compra de gêneros direcionados à dieta em instituições comerciais urbanas, são alguns traços centrais das causas dos distúrbios presentes nos regimes alimentares desta cidade.

Quanto aos alimentos tipicamente comercializados nas áreas urbanas, sublinha-se que, em sua maioria, são oriundos das indústrias, contendo elevadas taxas de conservantes e outros produtos químicos, os quais repercutem em diversos males aos seres humanos, conforme propaga Chiavenato (2005). No entanto, o autor adverte que os veículos midiáticos escamoteiam os males ocasionados pelo consumo destes produtos, através de estratégias vinculadas à publicidade e à propaganda dos mesmos, as quais ocultam suas facetas negativas.

Confrontando os resultados referentes à aplicação da EBIA no campo e na urbe em Nepomuceno, evidenciou-se maior quantidade de casos de insegurança alimentar entre os moradores citadinos, em comparação aos camponeses. Conferindo veracidade a tal afirmativa está o fato de inexistirem situações de insegurança alimentar moderada entre as famílias camponesas avaliadas, enquanto cinco domicílios urbanos apresentaram quadros deste nível de insegurança alimentar.

Além disto, o número de moradias em segurança alimentar na cidade é menor que o quantitativo de residências neste estado no campo nepomucenense. Este fato difere do panorama apurado pelo IBGE (2014) para o território nacional, no qual as taxas relativas de insegurança alimentar são maiores nas áreas rurais quando comparadas às urbanas.

Pela análise realizada, pôde-se constatar que uma das causas para a maior ocorrência de casos de insegurança alimentar na cidade em Nepomuceno, foi a parca diversidade de alimentos consumidos entre os habitantes urbanos do município, os quais relataram uma dieta alimentar direcionada principalmente à ingestão de fontes energéticas, em detrimento da obtenção de nutrientes essenciais à saúde humana. Ademais, percebeu-se entre os moradores das áreas urbanas uma profunda dependência do poder aquisitivo para o acesso aos víveres, enquanto os camponeses dispõem de terra propícia ao plantio, majorando a variedade de gêneros consumidos.

Com relação à EBIA, instrumento utilizado para averiguação da insegurança alimentar no município, as perguntas com maior quantitativo de respostas positivas entre os sujeitos citadinos, foram as questões 01,03 e 04 , denotando destarte, alguns dos motivos deteriorantes da alimentação na cidade.

Estes tópicos do questionário aplicado concernem respectivamente, ao medo de que os alimentos acabem antes da aquisição de mais víveres, à escassez de dinheiro para assegurar uma alimentação diversa e saudável, e à restrita variedade de gêneros consumidos em decorrência da ausência de proventos para comprá-los. Assim, com relação à escala adotada, pode-se afirmar que a insegurança alimentar na área urbana está entrelaçada à diminuta pluralidade de alimentos ingeridos e às reduzidas remunerações mensais.

Portanto, os valores de insegurança alimentar constatados em Nepomuceno, tanto na cidade, quanto no campo, são maiores em termos percentuais se contrapostos aos números nacionais, superando até mesmo os índices averiguados para as regiões Nordeste e Norte, as quais apresentam as situações mais agravadas da nação em termos alimentares.

Embora não existam quadros de fome global no município, a questão da variedade de alimentos consumidos é delicada, pois em praticamente todos os imóveis nos quais se averiguou insegurança alimentar, persistem problemas atinentes à diminuta diversidade de víveres constituintes das dietas. Portanto, se a pluralidade em seus regimes alimentares é restrita, é provável que os estados de fome oculta ou específica sejam vigorantes na conjuntura nepomucenense, em consequência de deficiências nutricionais.

Uma alimentação satisfatória em termos energéticos ou até mesmo a obesidade, não 
asseguram que todas as necessidades nutricionais do organismo sejam atendidas. Nestas conjunturas, conforme apontam os dizeres de Josué de Castro (1957), estabelecem-se estados de fome oculta e específica, os quais se caracterizam por deficiências nutricionais e avitaminoses, cujas consequências são deletérias à saúde humana, principalmente em razão das enfermidades causadas.

Nesta esfera, salienta-se que esta situação foi muito testemunhada no painel nepomucenense, pois nos imóveis com presença de obesos, a dieta alimentar não é diversa, tampouco contempla todas as substâncias necessárias ao corpo humano. Ademais, assim como acontece costumeiramente ao redor do mundo, privilegia-se o aspecto quantitativo da alimentação, em detrimento da variedade de gêneros consumidos.

Por último, ressalva-se que embora as condições de desnutrição tenham sido avaliadas neste estudo, estas não foram identificadas nas propriedades percorridas. Tal resultado foi consonante com a declaração da Secretaria Municipal de Saúde de Nepomuceno, a qual afirmou não haver nenhum caso registrado de desnutrição no município.

\section{CONSIDERAÇÕES FINAIS}

De acordo com o questionário aplicado da Escala Brasileira de Insegurança Alimentar, das quarenta famílias analisadas no campo em Nepomuceno, vinte e três $(57,5 \%)$ se encontram com segurança alimentar, dezessete $(42,5 \%)$ estão em insegurança alimentar leve, e nenhuma família se encontra em situação de insegurança alimentar moderada ou grave.

Já na cidade, das quarenta famílias pesquisadas, dezesseis (40\%) estão em segurança alimentar, dezenove $(47,5 \%)$ domicílios se encontram com insegurança alimentar leve, enquanto em cinco moradias (12,5\%), os moradores exibem situações de insegurança alimentar moderada. Nenhuma residência urbana investigada apresentou quadro de insegurança alimentar grave.

De maneira distinta ao cenário nacional, em Nepomuceno observou-se maior ocorrência de insegurança alimentar na cidade, em comparação ao campo. Amostra disto é o fato de cinco famílias citadinas estarem em estado de insegurança alimentar moderada, enquanto em nenhum imóvel camponês foi verificado tal panorama. Para além, o percentual averiguado de residências rurais com segurança alimentar no município é maior que o de moradias urbanas neste mesmo estado.

Portanto, os índices relativos de insegurança alimentar encontrados em Nepomuceno, na área urbana e na rural, são maiores que os detectados no país como um todo, até mesmo em regiões reconhecidamente pobres e caracterizadas por distúrbios alimentares, como o Norte e o Nordeste.

Através das entrevistas semiestruturadas, dos diálogos não estruturados, do cálculo do IMC e da caminhada transversal ou participativa, outros aspectos tangentes à insegurança alimentar foram avaliados na pesquisa 1, como a obesidade, o alcoolismo, o uso de pesticidas, entre outros. Destarte, observou-se uso intenso de agrotóxicos na agricultura familiar municipal, majorando os quadros de insegurança alimentar tanto dos pequenos produtores agrícolas, quanto dos consumidores de seus produtos.

O alcoolismo, assim como já articulado, compromete expressivamente a segurança alimentar dos lares. Nos quarenta imóveis rurais examinados neste estudo, foram constatados casos de alcoolismo em sete $(17,5 \%)$ deles, com acentuada presença entre os adultos jovens destas residências. É válido sublinhar, embasado nas narrativas dos sujeitos pesquisados, que houve representativa queda na quantidade de dependentes alcoólicos no campo municipal nos últimos anos.

Enquanto isto, nas quarenta moradias estudadas na urbe nepomucenense, apenas quatro 
$(10 \%)$ apresentaram quadros de alcoolismo entre seus habitantes, todos atingindo pessoas do sexo masculino. Para além, vários quadros de ex-alcoólatras foram descritos pelos habitantes citadinos de Nepomuceno. Assim sendo, nos imóveis analisados, o alcoolismo obteve índices maiores no campo, principalmente na faixa etária entre 18 e 25 anos. Tanto no campo, quanto na cidade, a dependência alcoólica acomete majoritariamente os homens.

Quanto à obesidade, característica determinadora da insegurança alimentar, dez (25\%) dos quarenta domicílios investigados no campo nepomucenense apresentaram indivíduos obesos, principalmente mulheres, as quais praticam menos exercícios físicos semanais, além de desempenharem funções cotidianas cujo dispêndio físico é inferior ao das atividades atribuídas aos homens.

$\mathrm{Na}$ cidade, foram observados casos de obesidade em dez (25\%) das quarenta famílias urbanas estudadas, com prevalência destes estados entre as mulheres das residências pesquisadas. Portanto, obteve-se o mesmo percentual de cidadãos obesos no campo e na cidade. Além disto, em ambas as áreas, a maioria das situações relatadas abrangia seres do sexo feminino.

\section{NOTAS}

1 - Este artigo é parte da dissertação de mestrado intitulada "Segurança Alimentar e Relações Capitalistas no Campo e na Cidade: O Exemplo de Nepomuceno-MG", apresentada junto ao Programa de Pós-Graduação em Geografia da Universidade Federal de Juiz de Fora, com financiamento da Coordenação de Aperfeiçoamento de Pessoal de Nível Superior.

\section{REFERÊNCIAS BIBLIOGRÁFICAS}

ABRASCO - Associação Brasileira de Saúde Coletiva. Dossiê Abrasco: Um alerta sobre o impacto dos Agrotóxicos na Saúde. Parte 1 - Agrotóxicos, Segurança Alimentar e Nutricional e Saúde. Rio de Janeiro: ABRASCO, 2012a.

Dossiê Abrasco: Um alerta sobre os impactos dos agrotóxicos na saúde. Parte 2 Agrotóxicos, Saúde, Ambiente e Sustentabilidade. Rio de Janeiro: ABRASCO, 2012b.

BOMBARDI, Larissa Mies. Intoxicação e morte por agrotóxicos no Brasil: a nova versão do capitalismo oligopolizado. Boletim DATALUTA. v. 45. 2011, p. 01-21.

CASTRO, Josué de. Geopolítica Da Fome. $4^{\text {a }}$ edição. São Paulo: Editora Brasiliense, 1957.

CHAMBERS, Robert. The Origins and Practice of Participatory Rural Appraisal. World Development. v. 22. n. 07. 1994, p. 953-969.

CHIAVENATO, Júlio José. O Massacre da Natureza. 2a edição reformulada. São Paulo: Editora Moderna, 2005. (Coleção Polêmica)

COSTA NETO, Canrobert. Agricultura familiar e renda da terra. Estudos Sociedade e Agricultura, n. 10, 1998, p. 118-134.

. "Relações entre agronegócio e agroecologia no contexto do desenvolvimento rural brasileiro.” In: FERNANDES, B.M. (Org.) Campesinato e Agronegócio na América Latina: a questão agrária atual. São Paulo: Expressão Popular, 2008, p. 71-82.

FERRARI, Eugênio Alvarenga. Agricultura Familiar Camponesa, Agroecologia e Estratégias de Reprodução Socioeconômica. Dissertação (Mestrado em Extensão Rural) Apresentada para Obtenção do Título de Magister Scientiae. Viçosa: Universidade Federal de Viçosa, 2010. 
FONSECA, Zulma Yanira; PATIÑO B, Gonzalo Alberto; HERRÀN F, Oscar Fernando. Malnutrición y seguridad alimentaria: un estudio multinivel. Revista Chilena de Nutrição. v. 40, n. 3, setembro, 2013, p. 206-215.

FREITAS, Maria do Carmo Soares de. Agonia da Fome. Rio de Janeiro, Salvador: FIOCRUZ, EDUFBA. 2003.

HARVEY, David. Os Limites do Capital. Tradução: Magda Lopes. São Paulo: Editora Boitempo, 2013.

HOFFMANN, Rodolfo. "Pobreza, insegurança alimentar e desnutrição no Brasil". In: GALEAZZI, M.A.M (Org.). Segurança alimentar e cidadania. Campinas: Mercado de Letras. 1996, p. 195-213.

IBGE - INSTITUTO BRASILEIRO DE GEOGRAFIA E ESTATÍSTICA. Pesquisa Nacional por Amostra de Domicílios (PNAD) de 2009. 2009.

Suplemento de Segurança Alimentar da PNAD - 2013. Rio de Janeiro. 2014.

MALUF, Renato S. Diversidad, Desigualdades y la Cuestión Alimentaria. Scripta Nova. Barcelona. n. 25. 1998. Disponível em: <http://www.ub.edu/geocrit/sn-25.htm> Acesso em: 22/06/2014

MALUF, Renato S. \& SPERANZA, Juliana. Volatilidade dos Preços Internacionais e Inflação de Alimentos no Brasil: Fatores Determinantes e Repercussões na Segurança Alimentar e Nutricional. Secretaria Nacional de Segurança Alimentar e Nutricional. Brasília, 2013, 148 p.

MANN, Peter H. Métodos de Investigação Sociológica. Tradução: Octavio Alves Velho. Rio de Janeiro: Editora Zahar, 1973.

MUNDO-ROSAS, Verónica; SHAMAR-LEVY, Teresa; RIVERA-DOMMARCO, Juan Á. Grupo de Seguridad Alimentaria en México. Epidemiología de la inseguridad alimentaria en México. Salud Pública de México / v. 55, supl. 2. 2013, p. 206-213.

OMS - ORGANIZAÇÃO MUNDIAL DA SAÚDE. Obesidad y Sobrepeso. Nota descritiva n 311. Janeiro de 2015. Disponível em: $<$ http://www.who.int/mediacentre/factsheets/fs311/es/> Acesso em: 03/05/2015.

OLIVEIRA, Maria Marly de. Como fazer pesquisa qualitativa. $4^{a}$ Edição. Petrópolis: Editora Vozes, 2012.

OLIVEIRA, Ariovaldo Umbelino de. A Mundialização da Agricultura Brasileira. São Paulo: Iãnde Editorial, 2016.

PESSOA, Vanira Matos. \& RIGOTTO, Raquel Maria. Agronegócio: geração de desigualdades sociais, impactos no modo de vida e novas necessidades de saúde nos trabalhadores rurais. Revista Brasileira de Saúde Ocupacional. São Paulo. v. 37. n. 125. 2012, p. 65-77.

PESSÔA, Vera Lúcia Salazar. Geografia e Pesquisa Qualitativa: um olhar sobre o processo investigativo. GeoUERJ. n. 23. v. 01. 2012, p. 04-18.

PIGNATI, Wanderlei Antonio; MACHADO, Jorge Mesquita Huet.; CABRAL, James F. Acidente rural ampliado: o caso das "chuvas" de agrotóxicos sobre a cidade de Lucas do Rio Verde-MT. Ciência \& Saúde Coletiva. Rio de Janeiro. v. 12. n. 01. 2007, p. 105-114.

PORTO-GONÇALVES, Carlos Walter. A Globalização da Natureza e a Natureza da Globalização. Rio de Janeiro: Editora Civilização Brasileira, 2006. 
PORTO-GONÇALVES, Carlos Walter. \& ALENTEJANO, Paulo. A Violência do Latifúndio Moderno-Colonial e do Agronegócio nos Últimos 25 Anos. Conflitos no Campo Brasil. v. 1. n. 1. 2009, p. 109-118.

RIGOTTO, Raquel Maria. Os conflitos entre o agronegócio e os direitos das populações: o papel do campo científico. Revista Pegada. v. 12. n. 01. 2011, p. 123-140.

SAMSEL, Anthony. \& SENEFF, Stephanie. Glyphosate, pathways to modern diseases III: Manganese. Neurological diseases and associated pathologies. International Journal of Neurosurgery and Neurosciences. v. 06. n. 45. 2015.

SEGALL-CORREAA, Ana Maria. Insegurança alimentar medida a partir da percepção das pessoas. Estudos Avançados. v. 21. n. 60. 2007, p. 143-154. Disponível em: $<$ http://www.scielo.br/pdf/ea/v21n60/a12v2160.pdf $>$ Acesso em: 01/06/2014.

SEGALL-CORRÊA, Ana Maria. \& MARIN-LEON, Letícia. A Segurança Alimentar no Brasil: Proposição e Usos da Escala Brasileira de Medida da Insegurança Alimentar (EBIA) de 2003 a 2009. Segurança Alimentar e Nutricional. Campinas. v. 16. n. 2. 2009, p.1-19.

SORLIE, Paul. D.; BACKLUND, Eric.; KELLER, Jacob. B. US mortality by economic, demographic, and social characteristics: The National Longitudinal Mortality Study. American Journal of Public Health. v. 85. n. 7. 1995, p. 949-956.

TRIVIÑOS, Augusto Nibaldo Silva. Introdução à Pesquisa em Ciências Sociais - A Pesquisa Qualitativa em Educação. 4a Edição. São Paulo: Editora Atlas, 1995.

VERVOORT, Joost.M., et al. Challenges to scenario-guided adaptive action on food security under climate change. Global Environment Change. v. 28, setembro, 2014, p. 383-394. Disponível em: $<$ http://dx.doi.org/10.1016/j.gloenvcha.2014.03.001> Acesso em: $25 / 06 / 2014$ 